\title{
AVALIAÇÃO MICROBIOLÓGICA DA FARINHA DE CARNE E OSSOS UTILIZADA NA AVICULTURA INDUSTRIAL NO NORDESTE DO BRASIL
}

José Andreey Almeida TELES ${ }^{1}$; Francisco Feliciano da SILVA JÚNIOR ${ }^{2}$; Sineide de Oliveira VILELA $^{3}$; Rebeka Correia de Souza CUNHA ${ }^{4}$; Mayara Layssa Timoteo dos SANTOS ${ }^{5}$; Gil Dutra FURTADO6; Aleudson dos Santos SILVA ${ }^{7}$

\begin{abstract}
${ }^{1}$ Graduado em Medicina Veterinária/Universidade Federal de Campina Grande (UFCG); Especialista em Doenças Infecto-contagiosas dos Animais Domésticos/Universidade Federal Rural de Pernambuco (UFRPE); Mestre em Biociência Animal (UFRPE); Doutor em Ciência Veterinária (UFRPE), Brasil. E-mail: teles.jaa@ gmail.com ${ }^{2}$ Graduado em Medicina Veterinária/Universidade Federal Rural de Pernambuco (UFRPE); Especialista em Clínica Médica dos Ruminantes/Universidade Estadual Paulista Júlio de Mesquita Filho (UNESP); Mestre em Medicina Veterinária Preventiva e Saúde Pública/Universidade Estadual Paulista Júlio de Mesquita Filho (UNESP); Doutor em Medicina Veterinária Preventiva e Saúde Pública/Universidade Estadual Paulista Júlio de Mesquita Filho (UNESP), Brasil. E-mail: felicianojr@yahoo.com.br

${ }^{3}$ Graduada em Medicina Veterinária/Universidade Federal Rural de Pernambuco (UFRPE); Mestre em Ciência Veterinária (UFRPE). Doutora em Ciência Veterinária (UFRPE), Brasil. E-mail: sineidevilela@ig.com.br
\end{abstract}

${ }^{4}$ Discente do $8^{\circ}$ período do Curso de Nutrição da Faculdade Maurício de Nassau, Brasil. E-mail: rebekacorreia0@gmail.com

${ }^{5}$ Discente do $8^{\circ}$ período do Curso de Medicina Veterinária do Centro Universitário Cesmac, Brasil. E-mail: mlayssa@outlook.com

${ }^{6}$ Discente do $2^{\circ}$ período do Curso de Medicina Veterinária da Faculdade Maurício de Nassau; Engenheiro Agrônomo/Universidade Federal da Paraíba (UFPB); Doutor em Psicobiologia/Universidade Federal do Rio Grande do Norte (UFRN); Agrônomo-Sócio da Cooperativa de Agronegócio (COOPAGRO), Brasil. E-mail: gdfurtado@hotmail.com

${ }^{7}$ Discente do $2^{\circ}$ período do Curso de Medicina Veterinária da Faculdade Maurício de Nassau, Brasil. E-mail: aleudson@gmail.com

Resumo. O Brasil tem se destacado constantemente na criação de aves, ocupando o terceiro lugar mundial em termos de produção e o primeiro em exportação. O Estado de Alagoas, Nordeste do Brasil, aloja um rebanho de 5.301.712, dos quais 1.354 .196 são galinhas. A nutrição de aves é um dos aspectos que têm melhorado bastante ao longo dos anos. O percentual de gastos com alimentação na criação de aves representa uma fatia significativa do investimento, de forma que é crescente a utilização de alimentos alternativos que são os subprodutos de matadouros (farinhas de origem animal como as de carne e ossos) como forma de suprir a demanda de minerais e de proteínas, além de reduzir o custo de produção. Contudo, um grande problema enfrentado muitas vezes pelos produtores de aves é a qualidade microbiológica desses produtos, uma vez que os mesmos podem veicular patógenos que causam grandes impactos na criação de aves. Esse trabalho objetivou analisar microbiologicamente as farinhas de carne 
e ossos (FCO) utilizadas na avicultura industrial no Estado de Alagoas. Foram avaliadas 179 amostras obtidas em fornecedores distintos. Desse total, 49,16\% estavam contaminadas por Clostridium perfringens, representando elevado risco quando de sua utilização na alimentação de aves. A quantidade de farinha de carne e ossos contaminadas com esta bactéria é elevada.

Palavras-chave: Contaminação; Subproduto; Galináceos: Salmonela; Clostridium.

\title{
MICROBIOLOGICAL EVALUATION OF FLOUR OF MEAT AND BONES USED IN INDUSTRIAL POULTRYING IN THE STATE OF ALAGOAS
}

\begin{abstract}
Brazil has consistently excelled in poultry, ranking third place worldwide the first in terms of production and exports. The State of Alagoas, Brazilian Northeast, houses a herd of 5.301.712, of whom 1.354.196 are chickens. The poultry nutrition is one of the aspects that have greatly improved over the years. The percentage of food expenditures in poultry represents a significant part of the investment, so that is increasing the use of alternative foods that are the byproducts of slaughterhouses (animal meal as meat and bone meal) as a way to meet the demand for minerals and proteins, as well as reducing the cost of production. However, a major problem faced often by poultry producers is the microbiological quality of these products, since they can carry pathogens that cause major impacts on poultry. This study aimed to analyze the microbiological flash flour and bone meal (FFBM) used in the poultry industry in the State of Alagoas. Were obtained 179 samples from different suppliers were evaluated. Of this total, $49.16 \%$ were contaminated by Clostridium perfringens representing a high risk when used in poultry feed. The quantity of meat and bone meal contaminated with this bacterium is high.
\end{abstract}

Keywords: Contamination; By-product; Gallinaceous; Salmonella; Clostridium.

\section{EVALUACIÓN MICROBIOLÓGICA DE HARINA DE CARNE Y HUESOS UTILIZADOS EN LA VULTA INDUSTRIAL EN EL ESTADO DE ALAGOAS}

Resumen. Brasil se ha destacado constantemente en las aves de corral, ocupando el tercer lugar a nivel mundial como el primero en términos de producción y exportaciones. El Estado de Alagoas, Nordeste de Brasil, alberga una manada de 5.301.712, de los cuales 1.354.196 son pollos. La nutrición avícola es uno de los aspectos que mejoró notablemente con el paso de los años. El porcentaje de gasto en alimentos en aves de corral representa una parte importante de la inversión, por lo que está aumentando el uso de alimentos alternativos que son los subproductos de los mataderos (harina animal como harina de carne y hueso) como una forma de satisfacer la demanda de minerales y proteínas, además de reducir el coste de producción. Sin embargo, un problema importante que enfrentan a menudo los productores de aves de corral es la calidad microbiológica de estos productos, ya que pueden transportar patógenos que causan impactos importantes en las aves. El objetivo de este estudio fue analizar la harina microbiana de pulpa y la harina de huesos (FFBM, por sus siglas en inglés) utilizada en la industria avícola en el estado de Alagoas. Se obtuvieron 179 muestras de diferentes proveedores. De este total, $49.16 \%$ fueron 
contaminados por Clostridium perfringens, lo que representa un alto riesgo cuando se usa en alimentos para aves. La cantidad de harina de carne y huesos contaminada con esta bacteria es alta.

Palabras clave: Contaminación; Subproducto; Galináceas; Salmonella; Clostridium.

\section{INTRODUÇÃO}

O Brasil ocupa o terceiro lugar mundial em termos de produção e o primeiro em exportação. Segundo dados do IBGE, o Brasil possui um rebanho de 1.266.466.046 de galináceos, desse total, 137.882.891 está na região Nordeste do país, por sua vez, o Estado de Alagoas aloja um rebanho de 5.301.712, dos quais 1.354.196 são galinhas (BRASIL, 2011).

A nutrição de aves é um dos aspectos que têm melhorado bastante ao longo dos anos. Considerando o elevado percentual que a alimentação representa no ciclo produtivo de aves, é cada vez maior a utilização de alimentos alternativos na elaboração de rações de frangos visando reduzir a eliminação de nutrientes no ambiente, além de atender cada vez mais em níveis satisfatórios os requerimentos nutricionais destes animais (PESSÔA et al., 2011; CARVALHO et al., 2012).

Os alimentos alternativos que possuem maior frequência de uso na alimentação de frangos são os subprodutos de matadouros (farinhas de origem animal como as de carne e ossos) como forma de suprir a demanda de minerais e de proteínas (SCHEUERMANN; ROSA, 2014; MATIAS et al., 2012; PEREIRA, 1993).

Por outro lado, a qualidade desses subprodutos deve ser a melhor possível, sendo necessário que os abatedouros se adéquem às normas de produção e inspeção higiênicosanitárias mencionadas na legislação vigente (MATIAS et al., 2012; HOLANDA, 2009).

Subprodutos de origem animal, antes de serem inseridos nas formulações de ração para aves devem ser submetidos à avaliação microbiológica uma vez que a qualidade é imprescindível para que não haja perdas produtivas (POLI-NUTRI, 2012).

Geralmente, o método de produção, que inclui, dentre outras etapas o tratamento térmico, é fundamental para garantir a qualidade microbiológica dessas farinhas (BRASIL, 2007).

Em termos de impactos econômicos gerados por falhas no manejo sanitário de aves, destacam-se os causados pela presença de micro-organismos como o Clostridium perfringens (JORGE, 1990). As perdas econômicas causadas por $C$. perfringens não surgem apenas pela mortalidade de aves no referido lote, mas é oriundo de vários fatores (PAULUS; RUCKEBUSCH, 1996; GAST, 1997). 
Nessa perspectiva, objetivou-se fazer a análise microbiológica frente à contaminação por $C$. perfringens das farinhas de carne e ossos utilizadas na avicultura industrial no Estado de Alagoas.

\section{MATERIAL E MÉTODOS}

Foram processados 179 espécimes de farinhas de carne e ossos obtidas em lotes produzidos por fornecedores dessas matérias para criatórios industriais de aves do Estado de Alagoas, Nordeste do Brasil. Os espécimes foram coletados e processados nos meses de maio e junho de 2014.

A coleta foi realizada de maneira asséptica, identificando e acondicionando as amostras de forma individual e transportando-as até o laboratório em caixas isotérmicas.

Os procedimentos de pré-enriquecimento foram feitos adicionando-se $25 \mathrm{~g}$ da amostra em $225 \mathrm{~mL}$ de água peptonada $0,1 \%$, obtendo-se aí a diluição inicial de $10^{-1}$. A partir daí, preparou-se as diluições $10^{-2}$ e $10^{-3}$.

Para o enriquecimento seletivo foram transferidas alíquotas do pré-enriquecimento para o ágar Shahidi-Ferguson Perfringens (SFP) e as placas, posteriormente, incubadas em estufa de crescimento bacteriano a $37^{\circ} \mathrm{C}$ por um período de 24 horas.

Após o período de incubação das placas, as colônias com aspectos macroscópicos característicos de Clostridium, foram identificadas e classificadas.

O cálculo do número de Unidade Formadora de Colônia - UFC/g foi realizado em função do número de colônias típicas e atípicas contadas, diluição inoculada e percentual de colônias confirmadas, conforme orientações técnicas de Brasil (2003).

\section{RESULTADOS E DISCUSSÃO}

Das 179 amostras de farinhas de carne e ossos avaliadas nesta pesquisa, 91 (50,84\%) foram coletadas e avaliadas no mês de maio e $88(49,16 \%)$ foram obtidas e processadas no mês de junho de 2014.

No geral, das 179 amostras analisadas, 88 delas $(49,16 \%)$ apresentaram contaminação, variando desde $100 \mathrm{UFC/g}$ até $10000 \mathrm{UFC} / \mathrm{g}$. Desses 88 espécimes, 35 (39,78\%) foram coletados no mês de maio e $53(60,22 \%)$ foram obtidas no mês de junho, demonstrando que, o último mês foi o que apresentou maior número de amostras impróprias à destinação do consumo pelas aves.

Esse valor mais elevado observado em detrimento ao mês de maio, provavelmente devese ao fato de a quantidade de amostras avaliadas no mês de junho também ter sido maior. 
Do total de 91 amostras que foram avaliadas em maio, $35(38,46 \%)$ apresentaram crescimento para $C$. perfringens. No mês de junho, 60,22\% das alíquotas de FCO testadas estavam contaminadas por esta bactéria.

Tais resultados demonstram que essas amostras de FCO, segundo a Resolução da Diretoria Colegiada (RDC) 12 de 2001, fazem parte de lotes impróprios para o consumo por animais.

Diferentemente do que se permite quanto à presença de Clostridium sulfito redutor em matérias-primas utilizadas na formulação de ração para aves, a RDC n 12 de 2001 reforça que qualquer quantidade de $C$. perfringens identificada em alimentos, o torna impróprio para consumo.

Quando a farinha é elaborada por graxarias, normalmente se utiliza como matéria prima, resíduos de carcaças de animais obtidos em açougues e supermercados. Contudo, não há controle das condições de estocagem do resíduo das carcaças até o momento de seu processamento, podendo haver comprometimento da qualidade final do produto. Nesses casos é onde pode haver o início da contaminação por micro-organismos que comprometerão a utilização das farinhas de origem animal como alimento.

PRIÓ et al. (2001) na Espanha, identificaram 33,6\% de contaminação por C. perfringens em um total de 109 amostras de farinha de carne, associando este achado ao fato de ocorrer contaminação muito facilmente por falhas no processamento ou na produção.

Ainda que as farinhas de origem animal tenham sido processadas e produzidas de forma correta, a qualidade microbiológica da ração pode ser comprometida pelo ambiente onde a mesma é fabricada, uma vez que a poeira presente no ambiente serve de veículo para patógenos contaminantes ou ainda podem promover condições como umidade a qual é fundamental para o desenvolvimento de agentes como fungos e bactérias (especialmente o C. perfringens).

\section{CONCLUSÕES}

A quantidade de farinhas de carne e ossos contaminadas com $C$. perfringens que é comercializada no Estado de Alagoas é elevada.

Os riscos inerentes a esta prática é significativa, tendo em vista o poder patogênico destruidor do micro-organismo, podendo comprometer a cadeia produtiva de aves.

Para se obter um resultado mais abrangente é preciso ampliar a avaliação de tais farinhas para os demais meses do ano. 
Suspeita-se que há deficiências relacionadas à fiscalização agropecuária, uma vez que todas as amostras analisadas eram pertencentes a lotes já comercializados, comprovando que o agente se faz presente em granjas de criação comercial localizadas no Estado de Alagoas.

\section{REFERÊNCIAS}

BRASIL. Instituto Brasileiro de Geografia e Estatística - IBGE. Produção Pecuária Municipal - PPM. Brasília (DF), 2011.

BRASIL. Empresa Brasileira de Pesquisa Agropecuária - EMBRAPA. Avaliação microbiológica da farinha de carne e ossos contendo flotado industrial de frigorífico. Comunicado técnico 464. Concórdia (SC), 2007.

CARVALHO, C.M.C. et al. Uso de farinhas de origem animal na alimentação de frangos de corte. Revista Portuguesa de Ciências Veterinárias. v. 107, n. 581-582, p. 69-73, 2012.

GAST, R.K. Paratyphoid Infections. In: Calnek BW. Diseases of Poultry, 10a ed. Ames: Iowa University Press. p. 97-121, 1997.

HOLANDA M.A.C. Avaliação nutricional da farinha de penas hidrolisada na alimentação de frangos de corte. 2009. Dissertação. Programa de Pós-Graduação em Zootecnia da Universidade Federal Rural de Pernambuco, Recife.

JORGE M.A. Cama de frango de corte: como fazer dela sua aliada na prevenção de enfermidades. In: Conferência Apinco de Ciência e Tecnologia Avícolas; São Paulo. São Paulo: Associação Brasileira dos Produtores de Pintos de Corte. p. 21, 1990.

MATIAS, C.F.Q. et al. Utilização de farinhas de origem animal na avicultura. Artigo número 175. Revista Eletrônica Nutritime. 2012; Disponível em: http://www.nutritime.com.br. Acesso em: 10 jun. 2018.

PAULUS, C.; RUCKEBUSCH, J.P. Enterite necrótica (NE) Zootecnica Internacional. Bologna. p. 40-3, 1996. 
PEREIRA, L.E.T. Farinha de vísceras de aves em substituição ao farelo de soja na alimentação de suínos em crescimento e terminação. 1993. Dissertação. Universidade Federal de Viçosa, Viçosa.

PESSÔA, G.B.S.; TAVERNARI, F.C.; VIEIRA, R.A.; ALBINO, L.F.T. Novos conceitos em nutrição de aves. XXI Congresso Brasileiro de Zootecnia - ZOOTEC; Maceió (AL). Universidade Federal de Alagoas. 2011.

POLI-NUTRI Nutrição Animal. Farinha de carne e ossos na alimentação de aves e suínos. 2012. Disponível em: http://www.polinutri.com.br. Acesso 26 jun. 2018.

SCHEUERMANN, G.N.; ROSA, P.S. Farinhas de origem animal na alimentação de monogástricos: a qualidade dos produtos define seu potencial de utilização. Boletim Pecuário; 2007 Disponível em: http://www.boletimpecuario.com.br/notes/noticia.php?n ot=ancora2744.boletimpecuario. Acesso em: 2 jun. 2018. 